\title{
Clonidine Toxicity: One or More Tablets can be Dangerous in Toddlers
}

\section{Sandesh Kini, Ramesh Bhat Y, Phalguna Kousika and Chennakeshava Thunga}

Department of Paediatrics, Kasturba Medical College, Manipal Academy of Higher Education, Manipal, Karnataka, India.

\section{Correspondence: \\ Ramesh Bhat Y \\ Department of Paediatrics \\ Kasturba Medical College, Manipal, \\ Manipal Academy of Higher Education, \\ Manipal, Karnataka, India \\ E-mail: ramesh.bhaty@manipal.edu}

DOI: $10.3126 /$ jnps.v39i1.23669

Submitted on: 2019-04-18

Accepted on: 2020-03-14

Acknowledgements: None

Funding: Nil

Conflict of Interest: None declared

Permission form IRB: Yes

\section{ABSTRACT}

Clonidine was a popular anti-hypertensive drug during the 1970s but is less commonly used now. In children clonidine is used to treat attention deficit hyperactive disorder (ADHD). We report a toddler who accidentally ingested $0.3 \mathrm{mg}$ of clonidine and developed respiratory failure with hypotension requiring ventilatory support and inotropes but recovered completely within one week. In any case scenario, when a previously healthy child presents with sudden onset respiratory failure, we should keep a high index of suspicion of clonidine use by anyone at home and its easy accessibility to the child.

Key words: clonidine; poisoning; toddler

To cite this article: Kini $S$, Bhat $R$, Kousika P, Thunga C. Clonidine toxicity: One or more tablets can be dangerous in toddlers. J Nepal Paediatr Soc. 2019;39(1):53-5.

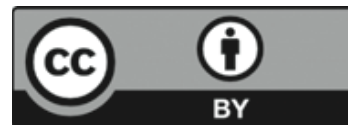

This work is licensed under creative common attribution 3.0 license 
as infusion was started. Child was intubated and mechanically ventilated in view of respiratory failure. Stomach wash was given and the gastric aspirate was sent for toxicology screening. Chest

\section{INTRODUCTION}

Clonidine is an imidazoline derivative which has alpha 1 and alpha 2 adrenoreceptor agonistic activity and has both central and peripheral action. ${ }^{1}$ Clonidine is widely used for the treatment of ADHD in children. Clonidine has a very narrow therapeutic index. Clonidine drug levels of 0.2 to $2 \mathrm{ng} / \mathrm{ml}$ can cause severe hypotension with half-life of 8-12 hours and the effect lasts till 24 hours. $^{2} \mathrm{~A}$ large case series on clonidine poisoning in children across six centres reported that a dose as minimum as $0.3 \mathrm{mg}(0.015 \mathrm{mg} / \mathrm{kg})$ can cause respiratory depression and coma. ${ }^{2}$ There are limited case reports from developing countries regarding clonidine poisoning, as this scenario is more common in the western world.

\section{CASE REPORT}

A two and half years old toddler boy was brought to our hospital with alleged history of consumption of three tablets of clonidine $0.1 \mathrm{mg}$ each. The tablets were being used by his grandfather for his medical illness. The child was given two to three spoons of cow's urine to induce vomiting within three minutes of ingestion. The child became unconscious within 10 minutes of ingestion and hence was rushed to the hospital within one hour. The child had no significant co-morbidities in the past and was developmentally normal.

At admission the child was lethargic with shallow respiratory efforts and depressed sensorium. Glasgow coma scale was E-1, V-1, M-1. His heart rate was 50 beats $/ \mathrm{min}$ with feeble peripheral pulses, blood pressure was $70 \mathrm{~mm} \mathrm{Hg}$ systolic, capillary refilling time $>3$ seconds, with intermittent apnoeic episodes. Oxygen saturation was $93 \%$ in room air. Pupils were bilaterally pin point. Child was hypotonic with absent deep tendon reflexes. His weight was $13 \mathrm{~kg}$ and length $95 \mathrm{~cm}$.

Child was shifted to the paediatric intensive care unit and given $20 \mathrm{ml} / \mathrm{kg}$ normal saline fluid bolus and atropine. In view of persistent hypotension despite fluid challenge, dopamine at $10 \mathrm{mcg} / \mathrm{kg} / \mathrm{min}$
$\mathrm{X}$-ray done after intubation showed collapse consolidation of right upper zone of lung which was suspected to be secondary to aspiration pneumonia. Hence injection cefoperazone and amikacin were started along with antiemetic and proton pump inhibitor. The investigations done at admission showed haemoglobin - $12.5 \mathrm{~g} / \mathrm{dL}$, total WBC count - 19000/ $\mu \mathrm{L}$, platelet count - 396000/ $\mu \mathrm{L}$, alanine transaminase - $18 \mathrm{IU} / \mathrm{L}$, aspartate amino transaminase- $36 \mathrm{IU} / \mathrm{L}$, serum creatinine$0.3 \mathrm{mg} / \mathrm{dL}$, serum sodium - $135 \mathrm{mmol} / \mathrm{L}$, serum potassium - $4 \mathrm{mmol} / \mathrm{L}$, random blood glucose-169 $\mathrm{mg} / \mathrm{dL}, \mathrm{C}$-reactive protein $-0.31 \mathrm{mg} / \mathrm{L}$. Arterial blood gas analysis done post intubation was as follows- $\mathrm{Ph}-7.39, \mathrm{pCO} 2-34.2 \mathrm{mmHg}, \mathrm{pO}_{2}-200$ $\mathrm{mmHg}, \mathrm{HCO} 3-21.5 \mathrm{mmol} / \mathrm{L}$, base excess- minus $3.5 \mathrm{mmol} / \mathrm{L}$. Toxicology screen of gastric aspirate tested positive for clonidine. Blood pressure and hemodynamic condition normalised within one hour of starting inotropes. Child's sensorium improved fully after 24 hours of hospitalisation and he had spontaneous breathing after 24 hours. Child was extubated after 36 hours. Oral feeding was started after 48 hours and inotropes were tapered and stopped by 48 hours. Antibiotics were continued for seven days along with supportive measures. Chest X-ray on day seven showed resolution of pneumonia. Child was discharged on day 8 and was advised regular follow up.

\section{DISCUSSION}

In this study we describe a toddler who accidentally consumed three tablets of clonidine $(0.02 \mathrm{mg} / \mathrm{kg})$ but was fortunate enough to be witnessed by his mother. Since the treatment was initiated within one hour, we were able to manage the respiratory failure and hypotension successfully with good outcome. Clonidine was initially developed as an anti-hypertensive agent in adults but recently it is being increasingly used in children for ADHD, aggression, tics and sleep disturbances. ${ }^{1}$ The epidemiology of clonidine poisoning differs between the developed and developing countries. In the developed countries most cases of poisoning are due to over dose of the child's own medication 
which is being used for paediatric behavioural disorders whereas in the developing countries it will be the adult's anti-hypertensive medication which will be accidentally consumed. ${ }^{3}$ Unintentional misdosing involving inadvertent double doses has been reported in $15 \%$ of patients in a case series. ${ }^{2}$ Most of the literature on clonidine poisoning have reported the onset of adverse events within four hours of ingestion with a mean time to maximum level of central nervous system depression of 1.7 hours (range: 1 to 3 hours) ${ }^{4}$ which is similar to our case. Most common adverse events reported are respiratory depression, coma and hypotension ${ }^{5}$ which is similar to our case. One study has reported myocardial ischemia after 24 hours with elevation in creatine kinase myocardial band (CK-MB) which normalised by day seven. ${ }^{6}$ Unfortunately there is no antidote to clonidine poisoning though some have used naloxone and treatment is mainly supportive care. ${ }^{5}$ There are reports of usage of naloxone in reversing the symptoms of clonidine toxicity, including depression of mental status and hypotension. ${ }^{7}$ However its use as an antidote remains controversial. Patients who respond to the initial dose of naloxone may have recurrent symptoms and require repeated doses or continuous infusion. ${ }^{7}$

Laboratory evaluation of plasma clonidine levels is not available as a routine test in many centres and sampling bias is possible with toxicology screening. Hence medical evaluation is recommended for all children four years of age and younger with unintentional clonidine ingestion of $\geq 0.1 \mathrm{mg},>0.2 \mathrm{mg}$ in children five-eight years of age and $\geq 0.4 \mathrm{mg}$ in children older than eight years. ${ }^{2}$ Four hours observation period is sufficient to detect the manifestations of adverse effects. ${ }^{2}$

\section{CONCLUSIONS}

From our study it is evident that respiratory failure can occur within ten minutes of clonidine overdose and only a careful history of drug exposure or usage by family members can clinch the diagnosis and aid in early initiation of supportive care.

\section{REFERENCES}

1. Basker S, Singh G, Jacob R. Clonidine In Paediatrics - A Review. Indian J Anaesth. 2009;53:270-80. PMID: 20640134

2. Spiller HA, Klein-Schwartz W, Colvin JM, Villalobos D, Johnson PB, Anderson DL. Toxic clonidine ingestion in children. J Paediatr. 2005;146(2):263-6. DOI: 10.1016/j.jpeds.2004.09.027

3. Klein-schwartz W. Trends and Toxic Effects From Paediatric Clonidine Exposures. Arch paediatr adolesc med. 2002;156:392-6. DOI: 10.1001/archpedi.156.4.392

4. Eddy O, Howell MJ. Are one or two dangerous? clonidine and topical imidazolines exposure in toddlers. The Journal of Emergency Medicine. 2003;25(3):297-302. DOI:10.1016/S0736-4679(03)00206-3.

5. Sinha Y. Clonidine poisoning in children : A recent experience. J Paediatr Child Health. 2004;(May):678-80. DOI: 10.1111/j. 1440-1754.2004.00491.x

6. Ambey R, Veerbhadra CD, Gupta R. Clonidine poisoning in a toddler. Journal of Dr. NTR University of Health Sciences. 2013;2(2):136-7. DOI: 10.4103/22778632.112349.

7. Kulig K, Rumack BH. Efficacy of naloxone in clonidine poisoning. Am J Dis Child. 1983; 137(8): 807. doi: 10.1001/archped;. 1983.02140340087028. 